Z. Klin. Chem. Klin. Biochem.

13. Jg. 1975 , S. $489-491$

\title{
Bestimmung des Serumkupfers mit der Atomabsorptionsspektrometrie
}

\author{
Von H. v. Campenhausen und O. Müller-Plathe \\ Aus dem Zentrallaboratorium (Chefarzt: Dr. O. Müller-Plathe) des Allgemeinen Krankenhauses Altona, Hamburg
}

(Eingegangen am 12. Mai/26. Juni 1975)

Zusammenfassung: Es wird eine vereinfachte Modifikation der atomabsorptionsspektrometrischen Serumkupferbestimmung mit Enteiweißung, jedoch ohne Inkubation bei $90^{\circ} \mathrm{C}$ angegeben. Das Verfahren zeichnet sich durch hohe Präzision und Richtigkeit sowie durch Linearität im gesamten klinisch interessanten Bereich aus.

\section{Determination of serum copper by atomic absorption spectrometry}

Summary: A simple modification of the atomic absorption method for the determination of serum copper is described, with deproteinization but without incubation at $90^{\circ} \mathrm{C}$. The method is characterized by high precision and accuracy, and it is linear throughout the clinically important range.

\section{Einführung}

Bei der Bestimmung des Serumkupfers nach dem von Olson \& Hamlin $(1,2)$ beschriebenen Verfahren wird nach erfolgter Enteiweißung mit Trichloressigsäure 15 Minuten lang bei $90^{\circ} \mathrm{C}$ inkubiert, anschließend zentrifugiert und der Uberstand zur Messung eingesetzt. Bei der nachfolgend beschriebenen Modifikation ergibt sich durch den Fortfall der Inkubation ein weniger störanfälliger Arbeitsgang, zudem werden höhere Extinktionen im Meßansatz erzielt.

\section{Material und Methoden \\ Geräte}

Atomabsorptionsspektrophotometer

Für die vorliegende Untersuchung wurde das Gerät FMD 3 der Firma Carl Zeiss, 7082 Oberkochen, verwendet.

Vibrationsmischer Whirlmix (Cenco Instruments, Breda, Niederlande)

\section{Reagenzien}

1. Cäsiumchlorịd z. A. (Merck Nr. 2038)

2. 3 mol/1 Trichloressigsäurelösung, etwa $40 \%$ (Merck 811)

3. Cation-Cal (Merz und Dade, 8 München 50, Lerchenstraße 5)

\section{Lösungen}

1. Enteiweißungslösung (Trichloressigsäure $1,5 \mathrm{~mol} / 1$, Cäsiumchlorid $3 \mathrm{mmol} / \mathrm{l}$ ). $250 \mathrm{mg}$ Cäsiumchlorid in $250 \mathrm{ml}$ Trichloressigsäure auflösen. Auffüllen mit doppelt destilliertem Wasser auf $500 \mathrm{ml}$.

2. Blindlösung. $100 \mathrm{ml}$ Lösung $1 \mathrm{mit} 400 \mathrm{ml}$ doppelt destilliertem Wasser mischen.

3. Standardlösung: Cation-Cal. Zweckmäßige Kupferkonzentration zur Kalibrierung um $30 \mu \mathrm{mol} / \mathrm{l}$.

\section{Methodik}

$\mathrm{Zu}$ 2,0 $\mathrm{ml}$ Serum oder Kalibrierlösung gibt man in schwermetallfrei gespülten Zentrifugengläsern unter ständiger Vibration auf dem Whirlmix $500 \mu$ l Enteiweißungslösung. 15 Minuten bei Raumtemperatur stehen lassen und anschließend scharf zentrifugieren. Der Uberstand wird direkt zur Messung der Extinktion angesaugt. Nullpunkteinstellung mit der Blindlösung.

Geräteeinstellungen (für FMD 3): Hohlkathodenlampe $\mathrm{Cu}$, Heizstrom $10 \mathrm{~mA}$.

Hohlkathodenlampe etwa 60 Minuten, Gerät mit Flamme etwa 15 Minuten einbrennen lassen.

Spalt $0,1 \mathrm{~mm}$

Sperrfilter 0

Wellenlänge $324,8 \mathrm{~nm}$

Brennerhöhe 8 Skalenteile

Luft 15,5 Skalenteile

Brenngas Acety len 7,0 Skalenteile

Anzeigefunktion E (Extinktion)

Berechnung:

$\frac{E_{\text {Probe }}}{\mathrm{E}_{\text {Standard }}} \cdot \mathrm{C}_{\text {Standard }}=\mu \mathrm{mol} / \mathrm{l} \mathrm{Cu}$

\section{Ergebnisse}

\section{Wiederfindungsversuche}

Da handelsübliche Kontrollseren mit Angabe des atomabsorptionsspektrometrisch gemessenen Kupfergehaltes nicht zur Verfugung stehen, wurde die Richtigkeit durch .. Wiederfindungsversuche untersucht (Abb. 1). Die Konzentrationen über $30 \mu \mathrm{mol} / 1$ wurden durch Zugabe einer konzentrierten Kupferlösung ( $394 \mu \mathrm{mol} / \mathrm{l})$, diejenigen unter $30 \mu \mathrm{mol} / \mathrm{l}$ wurden durch Verdünnung eines Pool-Serums mit Albuminlösung $(60 \mathrm{~g} / \mathrm{l})$ dargestellt. Die Eiweißkonzentration lag bei allen Versuchen 


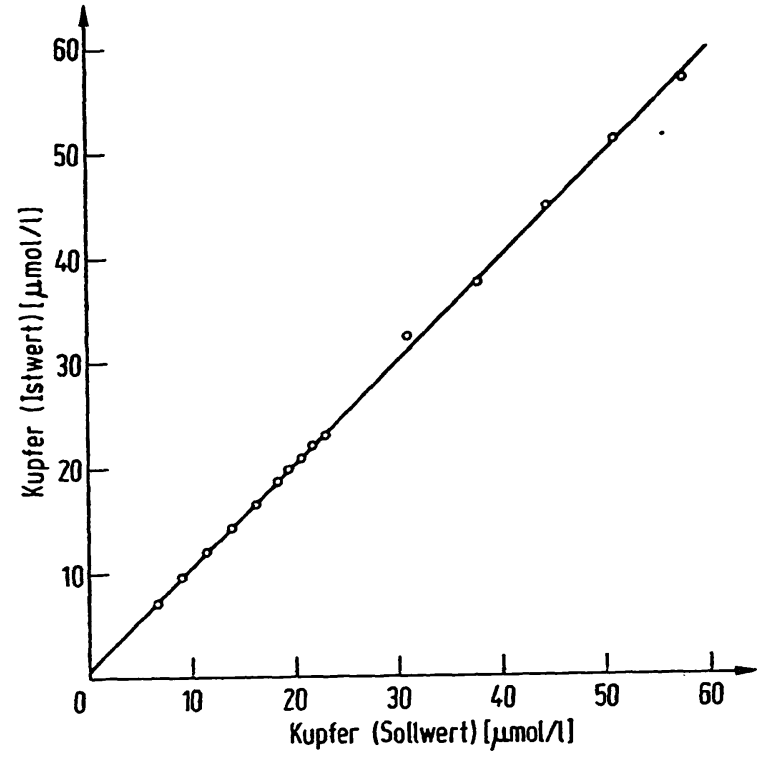

Abb. 1. Wiederfindungsversuche. 15 Doppelbestimmungen im Konzentrationsbereich von $6,6-57,6 \mu \mathrm{mol} / 1$. Abszisse: Sollwerte; Ordinate: Meßwerte. Regressionsgleichung: $y=0,725+0,979 x$

zwischen 50 und $75 \mathrm{~g} / 1$. Die Wiederfindung betrug bei 15 Versuchen im Konzentrationsbereich von 6,6 bis $57,6 \mu \mathrm{mol} / 1 \mathrm{im}$ Durchschnitt $101,75 \pm 2,44 \%$, wobei sich die größten Abweichungẹn (ungerichtet) im niedrigen Konzentrationsbereich unter $10 \mu \mathrm{mol} / 1$ fanden. Die Methode ist von 0 bis mindestens $60 \mu \mathrm{mol} / \mathrm{l}$, also im gesamten klinisch relevanten Bereich, linear (Abb. 1).

\section{Präzision}

Der Variationskoeffizient in der Serie beträgt $1,55 \%$ $(\bar{x}=23,25 \mu \mathrm{mol} / 1 ; \mathrm{s}=0,36 \mu \mathrm{mol} / 1 ; \mathrm{n}=22$ ).

Bei Untersuchungen von Tag zu Tag (über 4 Monate) errechnet sich ein Variationskoeffizient von 2,3\%. Die hohe Extinktion (etwa 0,1 im Bereich um 30-32 $\mu \mathrm{mol} / \mathrm{l}$ ) gewährleistet eine hohe Stabilität der Anzeige auch bei niedrigen Kupferkonzentrationen des Morbus Wilson.

\section{Vergleich mit der Bezugsmethode $(1,2)$}

Der Verzicht auf die Inkubation bei $90^{\circ} \mathrm{C}$ hat offenbar keinen wesentlichen Einfluß auf die Ergebnisse der Bestimmung (Abb. 2). Die entsprechende Regressionsgleichung lautet

$y=0,323+1,009 x$

Lediglich bei flüssigen Kontrollseren ergaben sich unterschiedliche Ergebnisse, nämlich regelmäßig etwas höhere Werte bei der $90^{\circ}$-Inkubation:

$$
\begin{array}{ll}
\text { für Lab-Trol } & +0,6 \mu \mathrm{mol} / 1=2,7 \%, \\
\text { für Patho-Trol } & +0,3 \mu \mathrm{mol} / 1=1,5 \%
\end{array}
$$

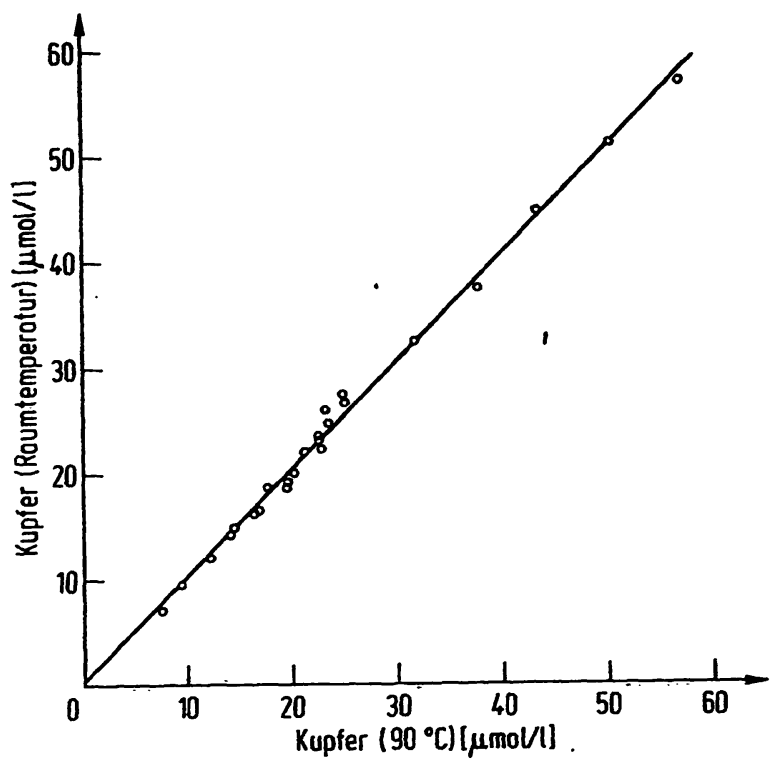

Abb. 2. Inkubation nach Eịweißpräzipitation bei Raumtemperatur (Ordinate) und bei $90^{\circ} \mathrm{C}$ (Abszisse). Vergleich der Ergebnisse.

Regressionsgleichung: $y=0,323+1,009 x$ Korrelation: $r^{2}=0,994$.

\section{Diskussion}

Wenn die Enteiweißung in der hier beschriebenen Weise als feinflockige Präzipitation auf dem laufenden Vibrationsmischer mit möglichst geringem Verdünnungseffekt durchgeführt wird, kann auf das Ërhitzen des Ansatzes verzichtet werden. Die Vorteile liegen auf der Hand:

Vereinf achung und Verkürzung des Arbeitsablaufes, Erhöhung der Präzision durch Fortfall unkontrollierbarer Verdampfungs- und Spritzeffekte sowie Vermeidung grober Verklumpung des Präzipitats bei der Hitzeeinwirkung. Wie die Wiederfindungsversuche beweisen, wird das Kupfer auch ohne Erhitzen vollständig aus der Eiweißbindung freigesetzt. Die Konzentration der Trichloressigsäure beträgt im Endansatz 0,3 mol/1 und liegt damit im üblichen Bereich (3). - Die Kupferbestimmung im nichtenteiweißten, sondern lediglich $1+1$ verdünntem Serum $(4,5)$ hat sich für Serienmessungen bei uns nicht bewährt.

Der Nachteil des hier geschilderten Vorgehens, das relativ große Probevolumen, kann unseres Erachtens zu Gunsten des hohen Meßsignals in Kauf genommen werden. Steht wenig Serum zur Verfügung, kann die Enteiweißung im Verhältnis 1:1 durchgeführt werden. Bei unverändertem Eichansatz müssen die so gewonnenen Ergebnisse mit dem Faktor 1,6 multipliziert werden.

An Stelle eines flüssigen eiweißhaltigen Standards, wie z. B. Cation-Cal, kann auch eine wäßrige Standardlösung treten. In diesem Falle ist jedoch ein Volumenverdrängungseffekt von etwa 5-6\% wegen der außerordentlich konzentriert dụ rchgeführten Enteiweißung in Rechnung zu stellen. 


\section{Literatur}

1. Olson, A. D. \& Hamlin, W. B. (1968), Atom. Abs. Newsl. 7, 69.

2. Olson, A. D. \& Hamlin, W. B. (1969), Clin. Chem. 15, 438444.

3. Richterich, R., Klinische Chemie, Verlag S. Karger, Basel 1971.
4. Sprague, S. \& Slavin, W. (1965), Atom. Abs. Newsl. 4, 228-233.

5. Heinemann, G. (1972), diese Z. 10, 467-472.

Dr. O. Müller-Plathe

Allgemeines Krankenhaus Altona 2000 Hamburg 50,

Paul-Ehrlich-Straße 1 
